\title{
Estimating hydroxytyrosol-tyrosol derivatives amounts in $c v$. Cobrançosa olive oils based on the electronic tongue analysis of olive paste extracts
}

\author{
Ítala M.G. Marx ${ }^{\mathrm{a}, \mathrm{b}}$, Susana Casal ${ }^{\mathrm{b}, * *}$, Nuno Rodrigues ${ }^{\mathrm{a}}$, Ana C.A. Veloso ${ }^{\mathrm{c}, \mathrm{d}}$, José A. Pereira ${ }^{\mathrm{a}}$, \\ António M. Peres ${ }^{\text {a, ** }}$ \\ ${ }^{a}$ Centro de Investigação de Montanha (CIMO), ESA, Instituto Politécnico de Bragança, Campus Santa Apolónia, 5300-253, Bragança, Portugal \\ ${ }^{\mathrm{b}}$ LAQV/REQUIMTE, Laboratory of Bromatology and Hydrology, Faculty of Pharmacy, University of Porto, Rua de Jorge Viterbo Ferreira, 228, 4050-313, Porto, \\ Portugal \\ ${ }^{\mathrm{c}}$ Instituto Politécnico de Coimbra, ISEC, DEQB, Rua Pedro Nunes, Quinta da Nora, 3030-199, Coimbra, Portugal \\ d CEB - Centre of Biological Engineering, University of Minho, Campus de Gualtar, 4710-057, Braga, Portugal
}

\section{A R T I C L E I N F O}

\section{Keywords:}

Lipid sensor membranes

Potentiometric profiles

Non-invasive indirect olive oil evaluation

Health claim

Multiple linear regression

\begin{abstract}
A B S T R A C T
The estimation of hydroxytyrosol-tyrosol derivatives amounts in olive oils through the analysis of olive pastes collected during malaxation is of utmost relevance due to the relationship with the oils' health claim regarding the protection of blood lipids from oxidative stress. Olive pastes were collected during the industrial extraction of cv. Cobrançosa oils (0-60 min; 22-34 $\left.{ }^{\circ} \mathrm{C}\right)$. Total phenolic contents of pastes' extracts were assessed (2800-5400 $\mathrm{mg} \mathrm{GAE} / \mathrm{kg}$ paste). Oils were laboratory-extracted from each paste and, after acid hydrolysis, the contents of hydroxytyrosol and tyrosol derivatives as their sum were determined (25-135, 62-120 and 68-255 mg/kg oil). Olive paste extracts were analyzed with a lab-made potentiometric electronic tongue. The device enabled estimating the total phenolic contents of the pastes (internal-validation: correlation coefficient $\geq 0.86$, root mean square error $\leq 392 \mathrm{mg} \mathrm{GAE} / \mathrm{kg}$ ). Moreover, the electronic tongue allowed a more satisfactory indirect estimation of the total secoiridoids derivatives amounts of the oils (internal-validation: correlation coefficient $\geq 0.91$, root mean square error $\leq 25 \mathrm{mg} / \mathrm{kg}$ ), based on the olive pastes' potentiometric profiles, without requiring the oils' posteriori invasive/destructive analysis. Thus, the electronic tongue could be foreseen as a potential tool for anticipating the health claim fulfilment during oils industrial extraction.
\end{abstract}

\section{Introduction}

Olive oil is a high-value food product, worldwide consumed due to its appreciated sensory attributes and documented nutritional and positive health effects, mainly related to the fatty acids and phenolics compositions (Marković, Torić, Barbarić, \& Brala, 2019; Servili et al., 2014). The physicochemical composition and sensory characteristics of an olive oil, and thus its quality grade (extra-virgin, virgin and lampante olive oil, i.e., EVOO, VOO and LOO, respectively), is greatly dependent of several factors, namely, olive cultivar, geographical origin, pre- and post-harvest agronomic/technological practices, fruit maturation index at harvest, extraction and storage conditions (Genovese, Yang, Linforth, Sacchi, \& Fisk, 2018; Gerhardt et al., 2019; Köseoğlu et al., 2016). The use of destructive and nondestructive analytical strategies (e.g., chromatography, spectroscopy, electrochemical sensor devices) to assess the physicochemical-sensory quality of olive oils and to identify/discriminate monovarietal oils, geographical origins or different types of adulteration, has been extensively reviewed (Aleixandre-Tudó, Castelló-Cogollos, Aleixandre, \& Aleixandre-Benavent, 2020; Kalogiouri, Aalizadeh, Dasenaki, \& Thomaidis, 2020; Marx et al., 2018; Meenu, Cai, \& Xu, 2019). However, the majority of the works deal with olive oil evaluation after extraction or storage. In those cases, the proposed methodologies were not used as prognostic oil quality tools, i.e., to predict the quality of the oil to be processed/being processed from measurements on the olive or in the processed olive collected during the oil extraction/malaxation process. In fact, few works have been published on the potential prediction of oil quality/composition before or during oil production. For example, Marquez, Herrera, Ojeda, and Maza (2009) and Funes, Allouche, Beltrán, Aguliera, and Jiménez (2017) designed artificial neural models using process variables from physical

\footnotetext{
* Corresponding author.

$* *$ Corresponding author.

E-mail addresses: sucasal@ff.up.pt (S. Casal), peres@ipb.pt (A.M. Peres).
} 
sensors and near infrared spectrum of olive pastes to predict EVOO characteristics. Ram, Wiesman, Parmet, and Edan (2010) applied image processing algorithms to photographs of olives together with olive quality features (size, shape, color, etc.) to predict the oil content. Allouche, López, Maza, and Márquez (2015) designed a sensor-software for real-time characterization of olive fruit (pulp/stone ratio, extractability index, moisture and oil contents), allowing predicting the potential characteristics of the extracted oil. This procedure required the correlation of variables related to olive fruit at the crushing stage with near infrared spectra from online scanned freshly milled olive paste. Kashiwagi, Kominami, Nakayama, and Kishimoto (2019) reported that the olive oil extraction yield could be predicted based on direct near infrared spectroscopy measurements of fresh olives. More recently, Martínez Gila, Gámez García, Bellincontro, Mencarelli, and Gómez Ortega (2020) used an electronic nose as a non-invasive technology to assess the post-harvest quality of olives, and applied it to predict the potential quality of the oil that would be processed (EVOO or VOO) from the same olives.

Estimating the alleged total hydroxytyrosol (Hyd) and tyrosol (Tyr) derivatives contents of the oils during the oil extraction process, based on the analysis of the related olive pastes, has a great relevance allowing anticipating the fullfillment of the health claim (EFSA, 2011; EU No $432 / 2012,2012$ ) regarding the olive oil polyphenols contribution to the protection of blood lipids from oxidative stress (minimum of $5 \mathrm{mg}$ of hydroxytyrosol and derivatives per $20 \mathrm{~g}$ of olive oil).

Thus, the present study aims to evaluate the possibility of using the electronic tongue (E-tongue) signals recorded during the potentiometric analysis of extracts of olive pastes, collected during the industrial oil extraction, to indirect and anticipatly estimate the Hyd and Tyr derivatives contents of olive oils of $c v$. Cobrançosa, based on the contents experimentally assessed on the pastes' oily fraction. This procedure would also allow inferring about the need of increasing (or not) a preestablished malaxation time. In this study, $c v$. Cobrançosa was selected since this cultivar is extensively grown in Portugal, being one of the prevailing olive cultivars in Trás-os-Montes region, which is the second most important Portuguese region regarding olive growing and oil production (Fernandes-Silva, López-Bernal, Ferreira, \& Villalobos, 2016). So, known amounts of olive pastes were collected from the malaxer at five time-periods (from 0 to $60 \mathrm{~min}$ ) and at three usual malaxation temperatures $\left(22,28\right.$ and $\left.34^{\circ} \mathrm{C}\right)$. The pastes' potentiometric profiles were acquired and afterwards tentatively correlated with the Hyd and Tyr contents, determined by HPLC-DAD, of the olive oils laboratory-extrated from those same pastes (pastes' oily fraction), which would allow antecipating the fulfillment of the oils' related health claim and minimizing, in the future, the need of using a chromatographic time-consuming procedure. Recently, the research team showed that $c v$. Cobrançosa oils industrially extracted during $60 \mathrm{~min}$ at different malaxation temperatures $\left(22-34{ }^{\circ} \mathrm{C}\right)$ supported the previously mentioned health claim (Marx, Casal, et al., 2021). It should be mentioned that E-tongues with lipid sensor membranes have been widely used to assess chemical (e.g., phenolic compounds and tocopherols) and sensory attributes of olive oils (Borges, Peres, Dias, Seiquer, \& Pereira, 2018; Marx, Rodrigues, et al., 2021; Rodrigues et al., 2019; Slim et al., 2017) and of other food-related matrices (Jeong et al., 2020; Toko, Hara, Tahara, Yasuura, \& Ikezaki, 2014; Yasuura, Shen, Tahara, Yatabe, \& Toko, 2015). These capabilities have been attributed to the lipid sensors' cross-sensitivity and low selectivity in-line with those of the human biological gustatory receptors (Wu, Tahara, Yatabe, \& Toko, 2020).

\section{Materials and methods}

\subsection{Olives, olive pastes and olive oil samples}

As previously described by Marx, Casal, et al. (2021), olives from the cv. Cobrançosa were harvested in mid-November 2018 from an orchard located in Trás-os-Montes region (northeast Portugal). Fruits were harvested with a maturity stage (MI) between two and three, which corresponds to the fruit epidermis with red spots in less than half of the olive (MI 2) and the fruit epidermis red or purple in more than half of the olive (MI 3), to minimize the influence of the MI. The industrial olive mill (OLIMONTES, Macedo de Cavaleiros, Portugal) comprised a two-phase unit (Alfa Laval, Italy) with a hammer crusher $(\sim 5000 \mathrm{~kg}$ of olives per h) and a sieve (11 mm of diameter) coupled with two malaxers (Type Gramula 700, $12 \mathrm{RPM}$ ), each one with 4 bodies ( $650 \mathrm{~kg}$ of paste), a two-phase horizontal decanter centrifuge ( $5000 \mathrm{~kg}$ of paste per $\mathrm{h}$ ), and a vertical centrifuge to wash and clean the olive oil (UVPX 507 AGT14). Olive pastes $(\sim 300 \mathrm{~g})$ were collected in triplicate from the malaxers during the industrial oil extraction, at three malaxation temperatures $\left(22,28\right.$ and $\left.34{ }^{\circ} \mathrm{C}\right)$ and at five time-periods $(0,15,30,45$ and $60 \mathrm{~min})$, totalizing 45 olive paste sub-samples ( 3 temperatures $\times 5$ time-periods $\times 3$ replicas), aiming to encompass the most common malaxation ranges usually applied during industrial olive oil extraction. Olive pastes were analyzed aiming to determine the total phenolic contents (TPC) and to establish the respective potentiometric profiles. On the other hand, oils were extracted, in the laboratory, from each of the 45 olive paste sub-samples and immediately chromatographically analyzed to determine the total contents of Hyd- and Tyr-derivatives, after acid hydrolysis.

\subsection{Olive pastes}

\subsubsection{Analytical extraction for total phenolics and potentiometric analysis}

Each olive paste subsample was homogenized and approximately $5 \mathrm{~g}$ of paste were mixed with $5 \mathrm{~mL}$ of $n$-hexane (vortex, $30 \mathrm{~s}$ ), followed by $25 \mathrm{~mL}$ of an aqueous methanolic solution $\left(\mathrm{MeOH} / \mathrm{H}_{2} \mathrm{O}\right.$ 80:20 v/v), vortex during 1-2 min (VWR $®$ Vortex Mixers, $230 \mathrm{~V}$ ) and centrifuged at 6000 RPM for $15 \mathrm{~min}$. The nonpolar fraction (upper phase) was discarded and the polar extract containing the phenolic compounds was collected to assess the TPC and to establish the potentiometric profiles.

\subsubsection{Total phenolic contents of olive paste extracts}

The TPC was determined following the methodology proposed by Singleton and Rossi (1965). Briefly, $1 \mathrm{~mL}$ of the extract obtained in section 2.2.1 was mixed with $1 \mathrm{~mL}$ of Folin-Ciocalteau reagent, and agitated in a vortex during $1 \mathrm{~min}$. Then $1 \mathrm{~mL}$ of saturate sodium carbonate $\left(\mathrm{Na}_{2} \mathrm{CO}_{3}\right)$ solution plus $7 \mathrm{~mL}$ of distilled water were added to the former mixture. The final mixture was kept in the dark for $90 \mathrm{~min}$, and then the absorbance was recorded at $725 \mathrm{~nm}$ with an UV-Vis spectrophotometer (GENESYS ${ }^{\mathrm{TM}} 10$, from Thermo Scientific ${ }^{\mathrm{TM}}$ ). The blank solution was obtained in a similar way, being the $1 \mathrm{~mL}$ of extracted substituted by $1 \mathrm{~mL}$ of aqueous methanolic solution $\left(\mathrm{MeOH} / \mathrm{H}_{2} \mathrm{O}\right.$ 80:20 $\mathrm{v} / \mathrm{v}$ ). Gallic acid (purity $\geq 99 \%$, from ExtraSynthese) was used as the external standard compound to establish the calibration curve (dynamic concentration range: $0.001-0.5 \mathrm{mg} / \mathrm{mL}, \mathrm{R}^{2}=0.9997$ ), being the results expressed as $\mathrm{g}$ of Gallic acid equivalent (GAE) per $\mathrm{kg}$ of olive paste ( $\mathrm{g}$ $\mathrm{GAE} / \mathrm{kg}$ olive paste).

\subsubsection{E-tongue apparatus and potentiometric analysis of olive paste extracts}

A lab-made potentiometric E-tongue multisensor device, comprising two cylindrical arrays (Rodrigues et al., 2019) was used to establish the potentiometric profiles of the olive pastes' aqueous methanolic diluted extracts. Each array comprised 20 lipid polymeric cross-sensitive sensor membranes (40 sensors in total), each corresponding to a different mixture of an additive compound (methyltrioctylammonium chloride, octadecylamine, oleic acid and oleyl alcohol) and a plasticizer (bis (1-butylpentyl) adipate, dibutyl sebacate, dioctyl phenylphosphonate, 2-nitrophenyl-octyl ether and tris(2-ethylhexyl) phosphate). The type of lipid polymeric sensors and the compositions were chosen due to: (i) the satisfactory signal stability over time (relative standard deviations, RSD, lower than $5 \%$ for a 5 -h time-period) for both standard solutions and real 
samples; (ii) the satisfactory intra- and inter-day repeatability $(0.1 \leq$ RSD $\leq 15 \%$ ) towards standard chemical solutions that mimicked the five basic taste sensations (sweet, acid, bitter, salty and umami) or olive oils' alcoholic aqueous extracts; and, (iii) their re-usability during at least one-year time period without requiring any replacement of the sensor membranes (Dias et al., 2009). Additionally, it has been found that these sensor membranes allowed establishing quantitative semi-logarithmic responses between the potentiometric signals and the concentration of different chemical compounds that mimic positive and negative sensory attributes usually perceived in olives or olive oils (Slim et al., 2017).

The E-tongue device was connected to an Agilent Data Acquisition unit (model 34970 A), which was controlled by an Agilent BenchLink Data Logger software. For the olive paste analysis, the polar $(\mathrm{MeOH} /$ water) extract obtained in section 2.2.1 was used. Briefly, $20 \mathrm{~mL}$ of aqueous methanolic extract was diluted to a final volume of $100 \mathrm{~mL}$, with deionized water, and mixed for 1-2 min in a vortex. Then, the solutions were immediately analyzed with the E-tongue, for 5-min, which allowed reaching a pseudo-equilibrium between the E-tongue non-specific lipid polymeric membranes and the chemical compounds present in each diluted extract solution. In fact, after 5 min of analysis the potentiometric signal of each lipid polymeric membrane reached an almost constant potential value (data not shown), showing that the equilibrium was reached, allowing a fast analysis time. After each assay the E-tongue was washed with deionized water. The E-tongue was further stored at room temperature and immersed into a $\mathrm{HCl}$ cleaning solution $(0.01 \mathrm{~mol} / \mathrm{L})$, which ensured the lipid polymeric membranes integrity and functionality during a long time-period (over one year).

\subsection{Olive oils}

\subsubsection{Olive oils laboratory-extracted from olive pastes}

From each homogenized olive paste, $2 \mathrm{~g}$ were collected and placed in Eppendorf tubes. The tubes were placed, during $10 \mathrm{~min}$, in an ultrasonic cleaner (Sonica) to promote cell breakdown and facilitate the extraction of the oil from the paste. Then, the samples were centrifuged (microcentrifuge Heraeus Fresco 1, Thermo Scientific) at 6000 RPM during 20 min, aiming to mimic the industrial extraction conditions used in the olive mill. The oil fraction (upper phase) was collected with a micropipette and the paste phase was discarded.

\subsubsection{Olive oils analytical extraction for the acid hydrolysis}

Phenolic compounds from the olive oil obtained after the laboratory extraction of each of the 45 olive pastes subsamples, were further analytically extracted and analyzed according to the method proposed by Romero and Brenes (2012) with some modifications. From each oil sample, $0.05 \mathrm{~g}$ were weighed, added with syringic acid (Sigma-Aldrich) as internal standard $(0.006 \mathrm{mg}$ from a $80: 20(\mathrm{v} / \mathrm{v})$ methanol/water solution at $0.15 \mathrm{mg} / \mathrm{mL}$ ). Then, $1 \mathrm{~mL}$ of a $2 \mathrm{~mol} / \mathrm{L}$ hydrochloric acid in methanol/water solution $(80: 20, \mathrm{v} / \mathrm{v})$ were added and agitated in a vortex mixer (Maxi Mix Plus, Thermolyne) during $30 \mathrm{~s}$. The solution was kept at $25{ }^{\circ} \mathrm{C}$ for $6 \mathrm{~h}$, being agitated periodically in a vortex. After $6 \mathrm{~h}$ of hydrolysis, $1 \mathrm{~mL}$ of an acetonitrile/water solution (50:50 v/v) were added and centrifuged (microcentrifuge Heraeus Fresco 17, Thermo Scientific) for $10 \mathrm{~min}$ at $13,000 \mathrm{RPM}$. After removal of the upper phase, $2 \mathrm{~mL}$ of the solution were transferred to a vial containing $2 \mathrm{~mL}$ of $n$-hexane. The mixture was stirred for $30 \mathrm{~s}$ in a vortex (Maxi Mix Plus, Thermolyne), centrifuged for $3 \mathrm{~min}$ at $3500 \mathrm{RPM}$ and filtered using a PVDF disposable filter $(0.22 \mu \mathrm{m})$.

\subsubsection{Olive oils total content of hydroxytyrosol and tyrosol derivatives after acid hydrolysis of secoiridoids}

The oils' phenolic profile was established using a HPLC-DAD system from Jasco (Japan) with a data transmitter (LC-NetII/ADC), two integrated pumps (PU-4180), an auto-sampler (AS-4050), a column oven (ECOM Eco2000, Czech Republic), and the DAD (MD-4010). The separation was accomplished on a C18 reversed-phase column (Kinetex
C18; particle size: $2.6 \mu \mathrm{m}$; pore size: $100 \AA$ A LC length: $100 \mathrm{~mm}$; internal diameter: $3.00 \mathrm{~mm}$, Phenomenex), at $35{ }^{\circ} \mathrm{C}$, using an eluent gradient composed of water and acetonitrile, both with $0.1 \%$ of formic acid, at a flow rate of $0.8 \mathrm{~mL} / \mathrm{min}$ for $20 \mathrm{~min}$. All samples were injected in duplicate totalizing 90 chromatographic results $(3$ temperatures $\times 5$ time-periods $\times 3$ olive paste samples $\times 1$ oil extraction $\times 1$ analytical extraction $\times 2$ chromatographic injections). The total hydroxytyrosol or tyrosol contents after hydrolysis were expressed as the individual sum in $\mathrm{mg}$ of hydroxytyrosol or tyrosol, respectively, per $\mathrm{kg}$ of oil. Hydroxytyrosol and tyrosol calibration curves $\left(R^{2}=0.9992\right.$ and 0.9990 , respectively) were prepared in methanol/water $(80: 20, \mathrm{v} / \mathrm{v})$ in a concentration range from 0.00031 to $0.0160 \mathrm{mg} / \mathrm{mL}$. Because after hydrolysis only the tyrosol and hydroxytyrosol moieties are quantified, loosing information on the molecular weight and structure of the original molecules, the original forms were estimated using the correction factors proposed in the literature for hydroxytyrosol (2.2) and tyrosol (2.5) (Mastralexi, Nenadis, \& Tsimidou, 2014; Tsimidou et al., 2019).

\subsection{Statistical analysis}

Data were expressed as mean \pm standard deviation values. The Pearson correlation coefficient ( $R$-Pearson) was determined to infer about the existence of a linear correlation between the TPC of olive pastes and the contents of Hyd- and Tyr-derivatives detected in the oils extracted from the olive pastes, after acid hydrolysis, independently of the malaxation temperature and the time-periods at which the olive pastes were sampled. Multiple linear regression (MLR) models, based on selected non-redundant E-tongue sensors identified using the simulated annealing (SA) algorithm, were developed aiming to evaluate the capability of estimating/predicitng the contents of Hyd- and Tyrderivatives of the oils laboratory-extracted using potentiometric data acquired from the analysis of olive pastes' aqueous methanolic diluted extracts. The accuracy of the E-tongue-MLR-SA models was established based on the correlation coefficients (R) and the root-mean-square errors (RMSE) for training and internal validation (leave-one-out crossvalidation, LOO-CV; and, repeated K-fold-CV) procedures. In this study, and as previously described (Borges et al., 2018), the repeated K-fold-CV procedure was implemented with 4 folds $(K=4)$ and 10 repeats (number of internal validations: 4 folds $\times 10$ repeats $=40$ validation runs, allowing that at each time, $25 \%$ of the dataset was randomly selected for validation purposes, being the remaining $75 \%$ of the data used for training purposes). The accuracy of the E-tongue-MLR-SA models was compared against the analytical conventional techniques used for assessing the TPC and total contents of Hyd- and Tyr-derivatives (Roig \& Thomas, 2003). All statistical analyzes were performed using the Sub-select (Cadima, Cerdeira, \& Minhoto, 2004) and MASS (Venables \& Ripley, 2002) packages of the open-source statistical program R (version 2.15.1), at a 5\% significance level.

\section{Results and discussion}

\subsection{TPC of olive pastes and Hyd-Tyr derivatives contents of oils laboratory-extracted from the olive pastes}

Table 1 shows the TPC, spectrophotometrically determined following the Folin-Ciocalteau method, of the olive pastes collected at five time-periods $(0,15,30,45$ and $60 \mathrm{~min})$ during the industrial extraction of $c v$. Cobrançosa oils at 22,28 and $34^{\circ} \mathrm{C}$. Table 1 also gives the total contents of the Hyd-derivatives, Tyr-derivatives and Hyd-Tyr derivatives, determined by HPLC-DAD, after acid hydrolysis, of the oils laboratory-extracted from the same olive pastes. It should be remarked that these latter contents were calculated using the correction factors proposed in the literature for Hyd and Tyr (Mastralexi et al., 2014; Tsimidou et al., 2019). As can be seen from Table 1, the contents determined at $0 \mathrm{~min}$ of malaxation, for the three malaxation temperatures studied, were different. Although the olives were from the same 
Table 1

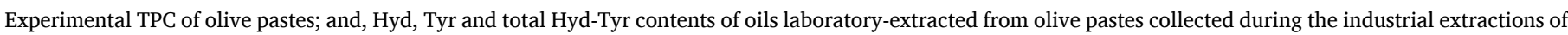
cv. Cobrançosa oils.

\begin{tabular}{|c|c|c|c|c|c|}
\hline \multirow{2}{*}{$\begin{array}{l}\text { Malaxation } \\
\text { temperature }\end{array}$} & \multirow{2}{*}{$\begin{array}{l}\text { Malaxation } \\
\text { time }\end{array}$} & \multirow{2}{*}{$\begin{array}{l}\text { TPC of olive pastes (mg GAE/kg olive } \\
\text { paste) }\end{array}$} & \multicolumn{3}{|c|}{ Olive oils extracted from the olive pastes ${ }^{\mathrm{b}}$} \\
\hline & & & $\begin{array}{l}\text { Hydroxytyrosol (mg/kg } \\
\text { oil) }\end{array}$ & $\begin{array}{l}\text { Tyrosol (mg/kg } \\
\text { oil) }\end{array}$ & $\begin{array}{l}\text { Hydroxytyrosol + Tyrosol (mg/kg } \\
\text { oil) }\end{array}$ \\
\hline \multirow[t]{5}{*}{$22{ }^{\circ} \mathrm{C}$} & $0 \mathrm{~min}$ & $2834 \pm 20$ & $25.5 \pm 8.5$ & $62.5 \pm 6.0$ & $88.0 \pm 2.6$ \\
\hline & $15 \mathrm{~min}$ & $4441 \pm 19$ & $71.1 \pm 0.5$ & $107.3 \pm 2.1$ & $178.4 \pm 1.6$ \\
\hline & $30 \mathrm{~min}$ & $4767 \pm 53$ & $42.8 \pm 9.6$ & $89.4 \pm 4.5$ & $132.2 \pm 12.4$ \\
\hline & $45 \mathrm{~min}$ & $5251 \pm 38$ & $126.1 \pm 3.2$ & $97.6 \pm 0.5$ & $233.6 \pm 2.6$ \\
\hline & $60 \mathrm{~min}$ & $5356 \pm 41$ & $134.7 \pm 0.9$ & $120.3 \pm 2.3$ & $255.1 \pm 1.4$ \\
\hline \multirow[t]{5}{*}{$28^{\circ} \mathrm{C}$} & $0 \mathrm{~min}$ & $3990 \pm 24$ & $20.4 \pm 4.8$ & $64.1 \pm 3.4$ & $84.5 \pm 1.4$ \\
\hline & $15 \mathrm{~min}$ & $4063 \pm 20$ & $27.2 \pm 8.6$ & $69.9 \pm 9.4$ & $97.2 \pm 13.5$ \\
\hline & $30 \mathrm{~min}$ & $4081 \pm 10$ & $50.6 \pm 5.0$ & $102.9 \pm 1.2$ & $153.5 \pm 5.2$ \\
\hline & $45 \mathrm{~min}$ & $3986 \pm 18$ & $61.4 \pm 9.9$ & $96.9 \pm 1.7$ & $158.3 \pm 10.2$ \\
\hline & $60 \mathrm{~min}$ & $4137 \pm 14$ & $82.7 \pm 9.9$ & $109.5 \pm 2.6$ & $192.2 \pm 12.5$ \\
\hline \multirow[t]{5}{*}{$34{ }^{\circ} \mathrm{C}$} & $0 \mathrm{~min}$ & $3036 \pm 11$ & $20.0 \pm 2.6$ & $47.6 \pm 3.3$ & $67.6 \pm 0.7$ \\
\hline & $15 \mathrm{~min}$ & $3287 \pm 9$ & $32.1 \pm 3.7$ & $59.2 \pm 5.2$ & $91.3 \pm 1.5$ \\
\hline & $30 \mathrm{~min}$ & $3669 \pm 15$ & $57.0 \pm 7.6$ & $87.3 \pm 8.5$ & $144.3 \pm 8.0$ \\
\hline & $45 \mathrm{~min}$ & $3870 \pm 15$ & $42.7 \pm 0.7$ & $100.7 \pm 9.0$ & $143.4 \pm 9.7$ \\
\hline & $60 \mathrm{~min}$ & $3384 \pm 22$ & $42.6 \pm 2.8$ & $62.4 \pm 7.8$ & $105.1 \pm 5.0$ \\
\hline
\end{tabular}

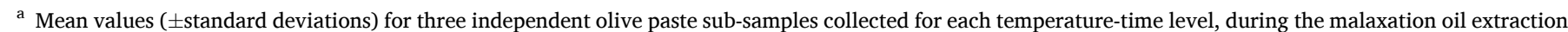

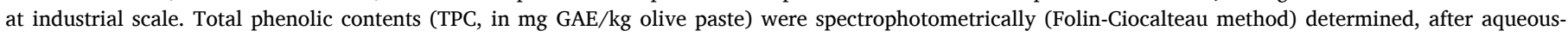
methanolic extraction of the pastes.

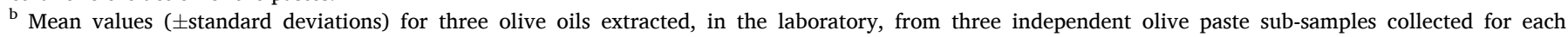

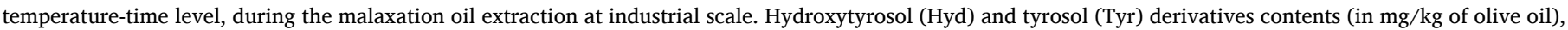

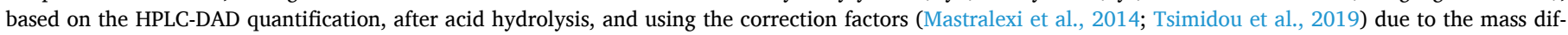
ferences between phenolic derivatives and the two simple compounds (hydroxytyrosol: 2.2; and, tyrosol: 2.5).

cultivar, collected at the same olive grove and had similar maturation index, it should be remarked that for each temperature assay, an independent batch of $\sim 650 \mathrm{~kg}$ of olives was used, which may lead to different phenolic composition of the obtained olive pastes and related oils. As can be inferred, the TPC of the studied pastes decreased with the increase of the malaxation temperature (from a mean value of 4530 to $3450 \mathrm{mg} \mathrm{GAE} / \mathrm{kg}$ olive paste for 22 and $34^{\circ} \mathrm{C}$, respectively; $R$-Pearson $=$ $-0.9978)$. On the other hand, for the studied temperatures and with some exceptions, olive pastes collected after higher malaxation time-periods were richer in TPC $(+0.9612 \leq R$-Pearson $\leq+0.9935)$. Similar trends were observed, in general, for the oils' Hyd- and Tyr-derivatives quantified after the acid hydrolysis. The contents of Hyd- and Tyr-derivatives as well as of the respective sum increased with the increase of the malaxation time at which the olive pastes were collected $(+0.9144 \leq R$-Pearson $\leq+0.9880)$ and, decreased with the increase of the malaxation temperatures $(-0.9948 \leq R$-Pearson $\leq$ -0.9555 ). Regarding the effect of malaxation time on the secoiridoids derivatives contents of olive oils, a similar increasing trend with time was reported by Gómez-Rico, Inarejos-García, Salvador, and Fregapane (2009) for Tyr-secoiridoids, but a decreasing trend was found for Hyd-secoiridoids. It should be noticed, that several researchers report a reduction of the TPC for oils extracted at higher malaxation times (Angerosa, Mostallino, Basti, \& Vito, 2001; Stefanoudaki, Koutsaftakis, \& Harwood, 2011). However, other researchers did not found significant differences of the phenolic contents of oils with the malaxation time (Kalua et al., 2007) or even reported an increase of the TPC with the increase of malaxation (Polari, Garcí-Aguirre, Olmo-García, Carrasco-Pancorbo, \& Wang, 2018). In which refers to the temperature trend observed for the oils studied, the results are in-line with those previously reported by Marx, Casal, et al. (2021) for $c v$. Cobrançosa oils extracted at industrial scale for the same range of malaxation temperatures and a malaxation time of $60 \mathrm{~min}$. However, it should be remarked that total contents of Hyd-Tyr-derivatives found in the oils laboratory-extracted (after $60 \mathrm{~min}$ ) were lower than those previously reported by Marx, Casal, et al. (2021), which were extracted at industrial-scale at the same malaxation conditions $(1.9 \times 2.5 \times$ and 4.3 $\times$ lower for 22,28 and $34{ }^{\circ} \mathrm{C}$, respectively). The lower contents found on laboratory-extracted oils could be tentatively attributed to the fact that these oils were analyzed within the 24-h after extraction and those industrially obtained were analyzed after 5 months of storage, being known that hydroxytyrosol and tyrosol contents increase along the storage time due to the hydrolysis of secoiridoids (Brenes, García, García, \& Garrido, 2001). On the other hand, has previously reported, oils of the same cultivar extracted at the same malaxation conditions but at different scales may have different phenolic contents (Inarejos-García, Gómez-Rico, Salvador, \& Fregapane, 2009).

Nevertheless, the results of the present study pointed out that the TPC of the olive pastes could be correlated with the total content of HydTyr-derivatives in the oils extracted from the same pastes, since an acceptable linear correlation could be established between these contents $(R$-Pearson $=+0.8232)$. However, since a non-specific method, prone to the interference of non-phenolic compounds, was used to assess the TPC of olive pastes, and the HPLC method was only used to determine the total contents of Hyd-Tyr-derivatives of the oils, the possible use of the aforementioned correlation as a predicitve tool must be viewed with precaution. Thus, an alternative approach, based on the use of a lab-made E-tongue was further evaluated.

3.2. Estimating TPC of olive pastes and the Hyd-Tyr derivatives contents of laboratory-extracted oils based on the potentiometric E-tongue analysis of olive paste extracts

The evaluation of the secoiridoidic fraction of the oils after acid hydrolysis has been established as a practical analytical procedure to assess the total content of Hyd- and Tyr-derivatives using suitable mass correction factors (Mastralexi et al., 2014). This knowledge allows, if desired, to verify the fulfillment of the possible health claim of a specific oil regarding the protection of blood lipids from oxidative stress (EFSA, 2011; EU No 432/2012, 2012). Thus, the capability of estimating/predicting the total content of Hyd- and Tyr-derivatives of an oil that is being processed from the evaluation of the respective olive paste (extract), during the malaxation step, would be of great commercial interest. In this context, diluted aqueous-methanolic extracts of olive pastes, collected during the industrial $c v$. Cobrançosa oil extraction, were analyzed using a lab-made E-tongue with 40 lipid sensor membranes. The analysis allowed establishing representative potentiometric 
profiles (40 signals for each olive paste sample collected at a different time-temperature of malaxation, varying from -83.5 to $+323.5 \mathrm{mV}$ ). These data were used to assess the TPC of the olive pastes and the total contents of Hyd- and Tyr-derivatives. For that, MLR models were developed based on non-redundant sub-sets of E-tongue sensors, selected using the SA algorithm. The analysis showed that two E-tongue-MLR-SA models, based on 13 or 24 E-tongue sensors, allowed the best fitting/prediction (LOO-CV and repeated K-fold-CV) of the TPC of the olive pastes and of the Hyd- and Tyr-derivatives contents of the laboratory-extracted oils, respectively, as shown in Table 2. As can be

Table 2

Predictive performance of E-tongue-MLR-SA models for: TPC in olive pastes; and, total contents of Hyd-Tyr-derivatives of oils laboratory-extracted from olive pastes collected during the industrial extractions of $c v$. Cobrançosa oils.

\begin{tabular}{|c|c|c|c|}
\hline & & $\begin{array}{l}\text { Olive pastes' } \\
\text { TPC }^{\mathrm{a}}\end{array}$ & $\begin{array}{l}\text { Olive oils' total content } \\
\text { of Hyd-Tyr derivatives }\end{array}$ \\
\hline Concentration range & & $\begin{array}{l}{[2800,5400]} \\
(\mathrm{mg} \mathrm{GAE} / \mathrm{kg} \\
\text { paste) }\end{array}$ & {$[68,255](\mathrm{mg} / \mathrm{kg}$ oil $)$} \\
\hline Number of sensors & & $13^{c}$ & $24^{\mathrm{d}}$ \\
\hline \multirow[t]{4}{*}{ Training $^{e}$} & $\mathrm{R}^{\mathrm{h}}$ & 0.9118 & 0.9935 \\
\hline & $\mathrm{RMSE}^{\mathrm{i}}$ & $\begin{array}{l}350 \mathrm{mg} \mathrm{GAE} / \mathrm{kg} \\
\text { paste }\end{array}$ & $9.8 \mathrm{mg} / \mathrm{kg}$ oil \\
\hline & Slope (IC) ${ }^{j}$ & $\begin{array}{l}0.831([0.716, \\
0.946])\end{array}$ & $0.987([0.951,1.023])$ \\
\hline & $\begin{array}{l}\text { Intercept } \\
\text { (IC) })^{\mathrm{k}}\end{array}$ & $\begin{array}{l}676([207, \\
1145])\end{array}$ & $1.8([-3.6,7.2])$ \\
\hline \multirow[t]{4}{*}{ LOO-CV ${ }^{\mathrm{f}}$} & $\mathrm{R}^{\mathrm{h}}$ & 0.8519 & 0.9329 \\
\hline & RMSE $^{\mathrm{i}}$ & $\begin{array}{l}380 \mathrm{mg} \mathrm{GAE} / \mathrm{kg} \\
\text { paste }\end{array}$ & $20.2 \mathrm{mg} / \mathrm{kg}$ oil \\
\hline & Slope (IC) ${ }^{j}$ & $\begin{array}{l}0.791([0.641 \\
0.940)]\end{array}$ & $0.971([0.851,1.091])$ \\
\hline & $\begin{array}{l}\text { Intercept } \\
(\mathrm{IC})^{\mathrm{k}}\end{array}$ & $\begin{array}{l}835([226, \\
1444])\end{array}$ & $2.0([-16.0,20.1])$ \\
\hline \multirow{4}{*}{ 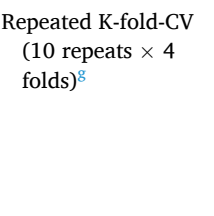 } & $\mathrm{R}^{\mathrm{h}}$ & $0.86 \pm 0.05$ & $0.91 \pm 0.08$ \\
\hline & RMSE $^{\mathrm{i}}$ & $\begin{array}{l}392 \pm 59 \mathrm{mg} \\
\mathrm{GAE} / \mathrm{kg} \text { paste }\end{array}$ & $25.3 \pm 9.6 \mathrm{mg} / \mathrm{kg}$ oil \\
\hline & Slope (IC) ${ }^{\mathrm{j}}$ & $\begin{array}{l}0.802([0.750, \\
0.853])\end{array}$ & $1.003([0.933,1.074])$ \\
\hline & $\begin{array}{l}\text { Intercept } \\
(\mathrm{IC})^{\mathrm{k}}\end{array}$ & $790([582,999])$ & $-3.5([-14.1,7.0])$ \\
\hline
\end{tabular}

a Total phenolic contents (TPC, in mg GAE/kg olive paste) spectrophotometrically (Folin-Ciocalteau method) determined, after aqueous-methanolic extraction of the pastes.

b Hydroxytyrosol (Hyd) and tyrosol (Tyr) derivatives total contents (in mg/kg of olive oil), quantified by HPLC-DAD analysis and using the correction factors (Mastralexi et al., 2014; Tsimidou et al., 2019), after acid hydrolysis of olive oils laboratory-extracted, from olive paste collected during industrial extraction at different malaxation temperatures-times.

c Number of sensors from the E-tongue selected using the SA algorithm and used to establish the best E-tongue-MLR-SA model (1st array: S1:1, S1:5, S1:6, S1:8, S1:14, S1:15, S1:19; 2nd array: S2:2, S2:4, S2:8, S2:11, S2:13, S2:15, S2:16, $\mathrm{S} 2: 20)$.

d Number of sensors from the E-tongue selected using the SA algorithm and used to establish the best E-tongue-MLR-SA model (1st array: S1:1, S1:2, S1:4 to S1:7, S1:10, S1:12, S1:14 to S1:19; 2nd array: S2:5, S2:6, S2:8, S2:9, S2:11 to S2:14, S2:16, S2:19).

e Modelling results regarding the training procedure (fitted data).

${ }^{f}$ Internal cross-validation variant: leave-one-out cross-validation (LOO-CV) procedure (one sample at a time is removed from the dataset and used to evaluate the predictive performance of the regression model established using the remaining. samples).

$\mathrm{g}$ Internal cross-validation variant: repeated K-fold cross validation (repeated K-fold-CV) procedure (the dataset is randomly split into K-folds, set equal to 4 , being one fold ( $25 \%$ of the data) used at a time for evaluating the predictive performance of the regression model established using the remaining folds, which process is repeated, in this study, 10 times).

$\mathrm{h}$ Correlation coefficient of the regression model (R).

i Root-mean-square error (RMSE).

j $95 \%$ slope confidence interval (IC).

k $95 \%$ intercept confidence interval (IC). inferred, the potentiometric signals gathered during the olive paste extracts analysis enabled a more accurate estimation of the total contents of Hyd- and Tyr-derivatives of the oils being produced (greater $\mathrm{R}$ values for both LOO-CV and repeated K-fold-CV), compared with the estimation of the TPC of the pastes (Fig. 1, for LOO-CV). Moreover, from the calculated 95\% confidence intervals (Table 2, which correspond to the single linear regressions between the predicted contents and the experimental data), it is clear that the E-tongue-MLR-SA model could predict the oils' total contents of Hyd-Tyr derivatives with a similar accuracy of the HPLC-DAD method (at 5\% significance level, the slope and intercept values were statistically equal to the expected theoretic values) (Roig \& Thomas, 2003). Contrary, the developed E-tongue based model could not be used to estimate the TPC of olive pastes, being less accurate than the Folin-Ciocalteau method. Finally, it should be remarked that the estimated Hyd-Tyr-derivatives contents of the $c v$. Cobrançosa oils based on the olive paste analysis would allow, in practical terms, to have a non-destructive/non-invasive and relatively fast (less than $30 \mathrm{~min}$ ) way of estimating the fulfillment of the health claim, regarding the protection of blood lipids from oxidative stress, of oils being produced, which would constitute a major advantage for oil producers and a quality guarantee for consumers. Nevertheless, to fully demonstrate the scope of the proposed methodology, future studies will be needed to establish E-tongue-MLR-SA models using olive pastes with a broader Hyd-Tyr-derivatives concentration range (greater than 250 $\mathrm{mg} / \mathrm{kg}$ ) as well as to highlight the relationship between the data collected from the olive pastes and the final quality of the extracted olive oils at commercialization time-period.

\section{Conclusions}

The assessment of the fulfillment of the olive oils' health claim, regarding the blood lipids protection against oxidative stress requires a chromatographic analysis, after the secoiridoids acid hydrolysis or after analysis of individual derivatives. Besides being a relatively timeconsuming method, it requires several non-green sample pretreatments, expensive equipment and skilled technicians. On the other hand, this conventional chromatographic technique has some practical limitations like the difficult in-situ and on-line implementation and its invasive/destructive characteristic, being only applied after the oil extraction. The present study showed that the potentiometric analysis of extracts of olive pastes, collected during the industrial extraction of $c v$. Cobrançosa oils, using a lab-made E-tongue coupled with multiple linear regression models, allowed to accurately predict the contents of hydroxytyrosol and tyrosol derivatives of the laboratory-extracted oils, and thus, to assess the oils potential health claim. The E-tongue based methodology, besides being a fast-analytical tool, did not required the direct analysis of the oils being produced and so, can be seen, in which the oil is concerned, as a non-invasive/non-destructive procedure. Taking into account its portability, the lab-made E-tongue could be easily used in an industrial olive mill environment allowing to estimate the health claim related phenolic contents of the oils that are being extracted from the preliminary analysis of the olive pastes. Although, the satisfactory results achieved can be seen as a proof-of-principle, the future application of the proposed sensor-based methodology would require the extension to other olive cultivars, to increase the covered concentration dynamic range, to clear demonstrate the relationship between olive paste and the related commercialized olive oil as well as to develop a direct olive paste analysis. Finally establishing a large dataset regarding olive pastes-olive oils industrially extracted would be of major interest, allowing an external full validation of the electronic tongue based approach as a future olive oils' health claim predicting device.

\section{CRediT authorship contribution statement}

Ítala M.G. Marx: Funding acquisition, Writing - original draft, 


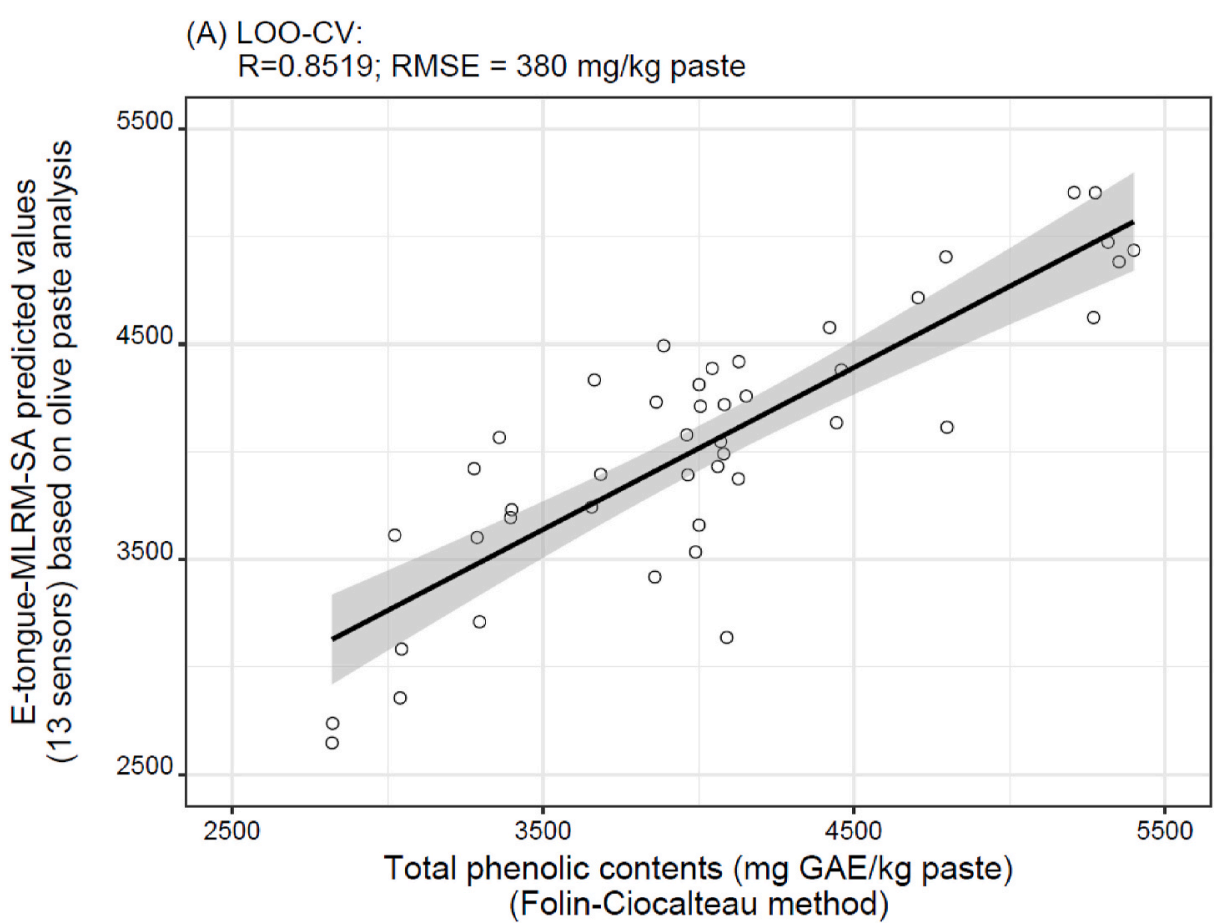

(B) LOO-CV: $\mathrm{R}=0.9329 ; \mathrm{RMSE}=20.2 \mathrm{mg} / \mathrm{kg}$ oil

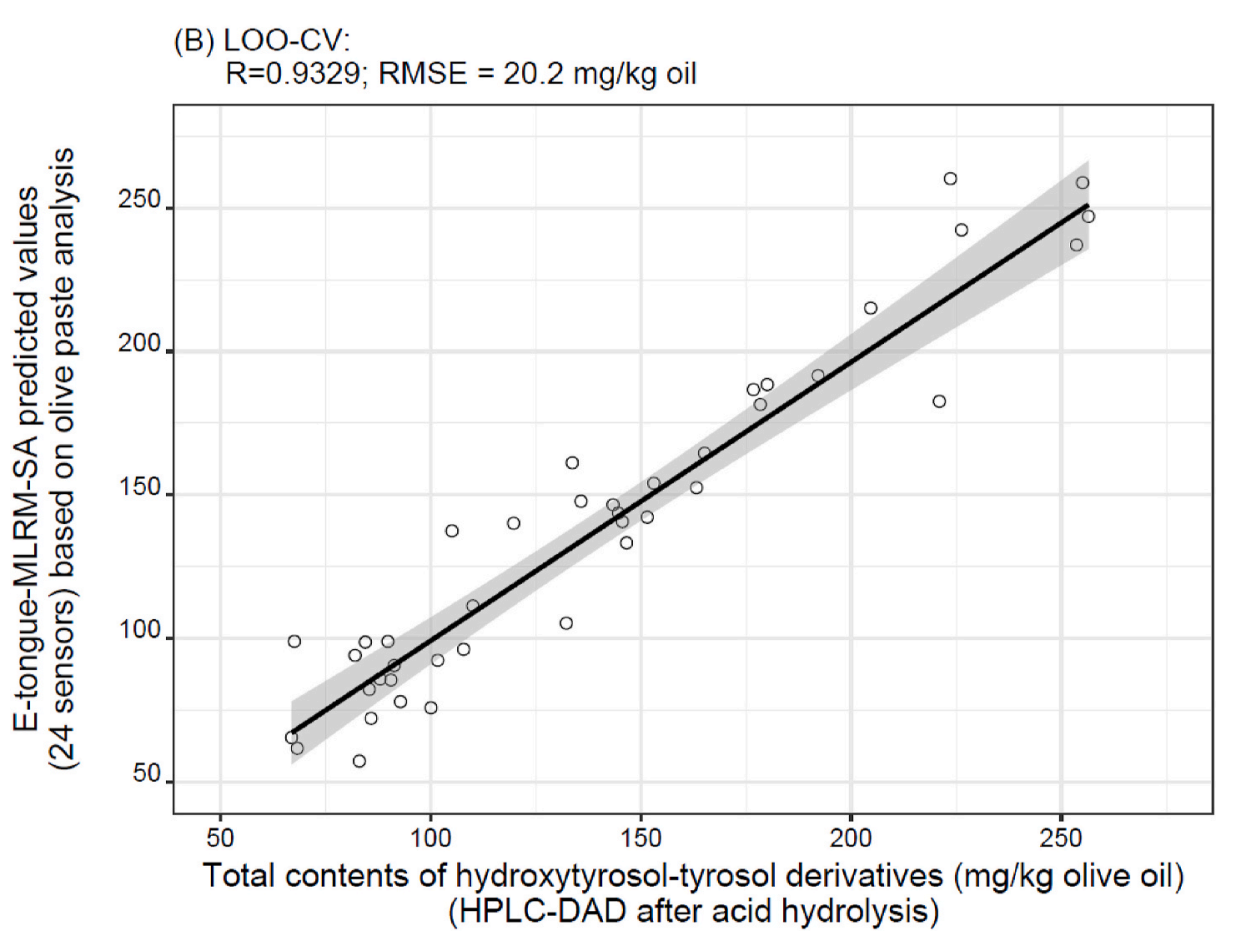

Fig. 1. Performance of the E-tongue-MLR-SA models based on non-redundant potentiometric profiles (selected by the SA algorithm) recorded during the analysis of olive pastes collected at different malaxation time/temperatures $(0,15,30$, 45 and $60 \mathrm{~min}$ at 22,28 and $34^{\circ} \mathrm{C}$ ) during the industrial extraction of $c v$. Cobrançosa oils. (A) Total phenolic contents (mg GAE/kg paste) of olive pastes estimated (LOO-CV) versus experimental data (Folin-Ciocalteau). (B) Total contents of hydroxytyrosol-tyrosol derivatives of olive oils laboratory-extracted from olive pastes estimated (LOO-CV) versus experimental data (HPLC-DAD after acid hydrolysis).
Acquisition of data, Analysis and/or interpretation of data, Drafting the manuscript, Revising the manuscript critically for important intellectual content, Approval of the version of the manuscript to be submitted. Susana Casal: Conceptualization, Writing - original draft, Conception and design the experiment, Analysis and/or interpretation of data, Drafting the manuscript, Revising the manuscript critically for important intellectual content, Approval of the version of the manuscript to be submitted. Nuno Rodrigues: Funding acquisition, Data curation, Acquisition of data, Analysis and/or interpretation of data, Revising the manuscript critically for important intellectual content, Approval of the version of the manuscript to be submitted. Ana C.A. Veloso: Funding acquisition, Data curation, Acquisition of data, Analysis and/or interpretation of data, Revising the manuscript critically for important intellectual content, Approval of the version of the manuscript to be submitted. José A. Pereira: Conceptualization, Writing - original draft, Conception and design the experiment, Analysis and/or interpretation of data, Drafting the manuscript, Revising the manuscript critically for important intellectual content, Approval of the version of the manuscript to be submitted. António M. Peres: Conceptualization, Writing original draft, Conception and design the experiment, Analysis and/or interpretation of data, Drafting the manuscript, Revising the manuscript critically for important intellectual content, Approval of the version of 
the manuscript to be submitted.

\section{Declaration of competing interest}

The authors declare that they have no conflict of interest.

\section{Acknowledgments}

The authors are grateful to the Foundation for Science and Technology (FCT, Portugal) for financial support by national funds FCT/ MCTES to CIMO (UIDB/00690/2020), to CEB (UIDB/04469/2020), to REQUIMTE-LAQV (UIDB/50006/2020) and to BioTecNorte operation (NORTE-01-0145-FEDER-000004) funded by the European Regional Development Fund under the scope of Norte2020 - Programa Operacional Regional do Norte. Ítala Marx acknowledges the Ph.D. research grant (SFRH/BD/137283/2018) provided by FCT. Nuno Rodrigues thanks the National funding by FCT- Foundation for Science and Technology, P.I., through the institutional scientific employment programcontract.

\section{References}

Aleixandre-Tudó, J. L., Castelló-Cogollos, L., Aleixandre, J. L., \& Aleixandre-Benavent, R. (2020). Bibliometric insights into the spectroscopy research field: A food science and technology case study. Applied Spectroscopy Reviews, 55(9), 873-906. https://doi. org/10.1080/05704928.2019.1694936

Allouche, Y., López, E. F., Maza, G. B., \& Márquez, A. J. (2015). Near infrared spectroscopy and artificial neural network to characterise olive fruit and oil online for process optimization. Journal of Near Infrared Spectroscopy, 23(2), 111-121. https://doi.org/10.1255/jnirs.1155

Angerosa, F., Mostallino, R., Basti, C., \& Vito, R. (2001). Influence of malaxation temperature and time on the quality of virgin olive oils. Food Chemistry, 72, 19-28. https://doi.org/10.1016/S0308-8146(00)00194-1

Borges, T. H., Peres, A. M., Dias, L. G., Seiquer, I., \& Pereira, J. A. (2018). Application of a potentiometric electronic tongue for assessing phenolic and volatile profiles of Arbequina extra virgin olive oils. LWT-Food Science and Technology, 93, 150-157. https://doi.org/10.1016/j.lwt.2018.03.025

Brenes, M., García, A., García, P., \& Garrido, A. (2001). Acid hydrolysis of secoiridoid aglycons during storage of virgin olive oil. Journal of Agricultural and Food Chemistry, 49, 5609-5614. https://doi.org/10.1021/jf0107860

Cadima, J., Cerdeira, J. O., \& Minhoto, M. (2004). Computational aspects of algorithms for variable selection in the context of principal components. Computational Statistics \& Data Analysis, 47(2), 225-236. https://doi.org/10.1016/j.csda.2003.11.001

Dias, L. A., Peres, A. M., Veloso, A. C. A., Reis, F. S., Vilas-Boas, M., \& Machado, A. A. S. C. (2009). An electronic tongue taste evaluation: Identification of goat milk adulteration with bovine milk. Sensors and Actuators B: Chemical, 136(1), 209-217. https://doi.org/10.1016/j.snb.2008.09.025

European Commission Regulation (EU) No 432/2012. (2012). Establishing a list of permitted health claims made on foods other than those referring to the reduction of disease risk and to children's development and health. Official Journal of the European Union, 1-40, L136.

European Food Safety Authority. (2011). EFSA Panel on Dietetic Products, Nutrition and Allergies. Scientific opinion on the substantiation of health claims related to polyphenols in olive oil and protection of LDL particles from oxidative damage. EFSA Journal, 9, 1-25. http://www.efsa.europa.eu/en/efsajournal/pub/2033.htm.

Fernandes-Silva, A. A., López-Bernal, Á., Ferreira, T. C., \& Villalobos, F. J. (2016). Leaf water relations and gas exchange response to water deficit of olive ( $c v$. Cobrançosa) in field grown conditions in Portugal. Plant and Soil, 402, 191-209. https://doi.org/ 10.1007/s11104-015-2786-9

Funes, E., Allouche, Y., Beltrán, G., Aguliera, M. P., \& Jiménez, A. (2017). A predictive artificial neural network model as a simulator of the extra virgin olive oil elaboration process. Journal of Near Infrared Spectroscopy, 25(4), 278-285. https://doi.org/ 10.1177/0967033517725639

Genovese, A., Yang, N., Linforth, R., Sacchi, R., \& Fisk, I. (2018). The role of phenolic compounds on olive oil aroma release. Food Research International, 112, 319-327. https://doi.org/10.1016/j.foodres.2018.06.054

Gerhardt, N., Schwolow, S., Rohn, S., Pérz-Cacho, P. R., Galán-Soldevilla, H., Arce, L., et al. (2019). Quality assessment of olive oils based on temperature-ramped HSGCIMS and sensory evaluation: Comparison of different processing approaches by LDA, kNN, and SVM. Food Chemistry, 278, 720-728. https://doi.org/10.1016/j. foodchem.2018.11.095

Gómez-Rico, A., Inarejos-García, A. M., Salvador, M. D., \& Fregapane, G. (2009). Effect of malaxation conditions on phenol and volatile profiles in olive paste and the corresponding virgin olive oils (Olea europaea L. Cv. cornicabra). Journal of Agricultural and Food Chemistry, 57(9), 3587-3595. https://doi.org/10.1021/ jf803505w

Inarejos-García, A., Gómez-Rico, A., Salvador, M. D., \& Fregapane, G. (2009). Influence of malaxation conditions on virgin olive oil yield, overall quality and composition.
European Food Research and Technology, 228, 671-677. https://doi.org/10.1007/ s00217-008-0977-9

Jeong, H.-M., Kwon, H.-C., Xu, B., Jung, D., Han, M., Kwon, D.-H., et al. (2020). Taste sensor based on the floating gate structure of a lateral double-diffused metal-oxide semiconductor. Sensors and Actuators B: Chemical, 308, 127661. https://doi.org/ 10.1016/j.snb.2020.127661

Kalogiouri, N. P., Aalizadeh, R., Dasenaki, M. E., \& Thomaidis, N. S. (2020). Application of High Resolution Mass Spectrometric methods coupled with chemometric techniques in olive oil authenticity studies - a review. Analytica Chimica Acta, 1134, 150-173. https://doi.org/10.1016/j.aca.2020.07.029

Kalua, C. M., Allen, M. S., Bedgood, D. R., Bishop, A. G., Prenzler, P. D., \& Robards, K. (2007). Olive oil volatile compounds, flavour development and quality: A critical review. Food Chemistry, 100(1), 273-286. https://doi.org/10.1016/j. foodchem.2005.09.059

Kashiwagi, A., Kominami, R., Nakayama, S., \& Kishimoto, N. (2019). Nondestructive prediction of oil yield through direct near infrared spectroscopy measurements of fresh olives. ISOEN 2019 - 18th international symposium on olfaction and electronic nose. Proceedings, 8823467. https://doi.org/10.1109/ISOEN.2019.8823467

Köseoğlu, O., Sevim, D., \& Kadiroğlu, P. (2016). Quality characteristics and antioxidant properties of Turkish monovarietal olive oils regarding stages of olive ripening. Food Chemistry, 212, 628-634. https://doi.org/10.1016/j.foodchem.2016.06.027

Marković, A. K., Torić, J., Barbarić, M., \& Brala, C. J. (2019). Hydroxytyrosol, tyrosol and derivatives and their potential effects on human health. Molecules, 24(10), 2001. https://doi.org/10.3390/molecules24102001

Marquez, A. J., Herrera, M. P. A., Ojeda, M. U., \& Maza, G. B. (2009). Neural network as tool for virgin olive oil elaboration process optimization. Journal of Food Engineering, 95(1), 135-141. https://doi.org/10.1016/j.jfoodeng.2009.04.021

Martínez Gila, D. M., Gámez García, J., Bellincontro, A., Mencarelli, F., \& Gómez Ortega, J. (2020). Fast tool based on electronic nose to predict olive fruit quality after harvest. Postharvest Biology and Technology, 160, 111058. https://doi.org/ 10.1016/j.postharvbio.2019.111058

Marx, Í. M. G., Casal, S., Rodrigues, N., Pinho, T., Veloso, A. C. A., Pereira, J. A., et al. (2021). Impact of the malaxation temperature on the phenolic profile of $c v$. Cobrançosa olive oils and assessment of the related health claim. Food Chemistry, 337, 127726. https://doi.org/10.1016/j.foodchem.2020.127726

Marx, Í. M. G., Rodrigues, N., Veloso, A. C. A., Casal, S., Pereira, J. A., \& Peres, A. M. (2021). Effect of malaxation temperature on the physicochemical and sensory quality of $c v$. Cobrançosa olive oil and its evaluation using an electronic tongue. LWT-Food Science and Technology, 137, 110426. https://doi.org/10.1016/j. lwt.2020.110426

Marx, Í. M. G., Veloso, A. C. A., Dias, L. G., Casal, S., Pereira, J. A., \& Peres, A. M. (2018). Electrochemical sensor-based devices for assessing bioactive compounds in olive oils: A brief review. Electronics, 7(12), 387. https://doi.org/10.3390/ electronics7120387

Mastralexi, A., Nenadis, N., \& Tsimidou, M. Z. (2014). Addressing analytical requirements to support health claims on "olive oil polyphenols" (EC regulation 432/2012). Journal of Agricultural and Food Chemistry, 62, 2459-2461. https://doi. org/10.1021/jf5005918

Meenu, M., Cai, Q., \& Xu, B. (2019). A critical review on analytical techniques to detect adulteration of extra virgin olive oil. Trends in Food Science \& Technology, 91, 391-408. https://doi.org/10.1016/j.tifs.2019.07.045

Polari, J. J., Garcí-Aguirre, D., Olmo-García, L., Carrasco-Pancorbo, A., \& Wang, S. C. (2018). Interactions between hammer mill crushing variables and malaxation time during continuous olive oil extraction. European Journal of Lipid Science and Technology, 120(8), 1800097. https://doi.org/10.1002/ejlt.201800097

Ram, T., Wiesman, Z., Parmet, I., \& Edan, Y. (2010). Olive oil content prediction models based on image processing. Biosystems Engineering, 105(2), 221-232. https://doi. org/10.1016/j.biosystemseng.2009.10.011

Rodrigues, N., Marx, Í. M. G., Casal, S., Dias, L. G., Veloso, A. C. A., Pereira, J. A., et al. (2019). Application of an electronic tongue as a single-run tool for olive oils' physicochemical and sensory simultaneous assessment. Talanta, 197, 363-373. https://doi.org/10.1016/j.talanta.2019.01.055

Roig, B., \& Thomas, O. (2003). UV monitoring of sugars during wine making. Carbohydrate Research, 338, 79-83. https://doi.org/10.1016/S0008-6215(02) 00396-8

Romero, C., \& Brenes, M. (2012). Analysis of total contents of hydroxytyrosol and tyrosol in olive oils. Journal of Agricultural and Food Chemistry, 60, 9017-9022. https://doi. org/10.1021/jf3026666

Servili, M., Sordini, B., Esposto, S., Urbani, S., Veneziani, G., Di Maio, I., et al. (2014). Biological activities of phenolic compounds of extra virgin olive oil. Antioxidants, 3, 1-23. https://doi.org/10.3390/antiox3010001

Singleton, V. L., \& Rossi, J. A. (1965). Colorimetry of total phenolics with phosphomolybdic-phosphotungstic acid reagents. American Journal of Enology and Viticulture, 16, 144-158.

Slim, S., Rodrigues, N., Dias, L. G., Veloso, A. C. A., Pereira, J. A., Oueslati, S., et al. (2017). Application of an electronic tongue for Tunisian olive oils' classification according to olive cultivar or physicochemical parameters. European Food Research and Technology, 243, 1459-1470. https://doi.org/10.1007/s00217-017-2856-8

Stefanoudaki, E., Koutsaftakis, A., \& Harwood, J. L. (2011). Influence of malaxation conditions on characteristic qualities of olive oil. Food Chemistry, 127(4), 1481-1486. https://doi.org/10.1016/j.foodchem.2011.01.120

Toko, K., Hara, D., Tahara, Y., Yasuura, M., \& Ikezaki, H. (2014). Relationship between the amount of bitter substances adsorbed onto lipid/polymer membrane and the electric response of taste sensors. Sensors, 14(9), 16274-16286. https://doi.org/ $10.3390 /$ s140916274 
Tsimidou, M. Z., Nenadis, N., Mastralexi, A., Servili, M., Butinar, B., Vichi, S., et al. (2019). Toward a harmonized and standardized protocol for the determination of total hydroxytyrosol and tyrosol content in virgin olive oil (VOO). The pros of a fit for the purpose ultra high-performance liquid chromatography (UHPLC) procedure. Molecules, 24(13), 2429. https://doi.org/10.3390/molecules24132429

Venables, W. N., \& Ripley, R. B. (2002). Modern applied statistics with $S$ (statistics and computing) (4th ed.). New York: Springer. https://doi.org/10.1007/978-0-38721706-2
Wu, X., Tahara, Y., Yatabe, R., \& Toko, K. (2020). Taste sensor: Electronic tongue with lipid membranes. Analytical Sciences, 36, 147-159. https://doi.org/10.2116/ analsci.19R008

Yasuura, M., Shen, Q., Tahara, Y., Yatabe, R., \& Toko, K. (2015). Development and investigation of a sweetness sensor for sugars - effect of lipids. Sensors and Materials, 27(5), 351-358. https://doi.org/10.18494/SAM.2015.1073 